\title{
Benefits of using amorphous metallic fibres in concrete slabs-on-grade
}

\author{
Sunitha K. Nayar ${ }^{a}$, Ravindra Gettua* \\ ${ }^{\text {a }}$ Department of Civil Engineering, Indian Institute of Technology Madras, Chennai, India - 600036
}

Received: 13 November 2016 / Accepted: 30 December 2016 / Published online: 31 December 2016

C The Author(s) 2016. This article is published with open access.

\begin{abstract}
The effective utilization of pseudo-ductile materials like Fibre Reinforced Concrete (FRC) depends on the incorporation of suitable material parameters in appropriate design approaches. A design methodology has been developed for slabs-on-grade addressing various failure patterns, and giving a performance requirement as the design output. This opens up the choice of fibres, allowing the use of combinations of fibres to suit the service requirements. In this context, the current study explores the use of hybrid combinations of conventional steel fibres (SF) and a genre of corrosionresistant amorphous metallic fibres (AMF) that have the ability to significantly enhance the flexural strength of concrete, even at relatively low dosages. It is shown that AMF, when used in combination with SF, results in a synergistic response with respect to toughness; mixes with $15 \mathrm{~kg} / \mathrm{m}^{3}$ of $\mathrm{SF}$ and $20 \mathrm{~kg} / \mathrm{m}^{3}$ of AMF exhibit about $50 \%$ higher characteristic flexural strength and more than double the characteristic equivalent flexural strength than the mix with $15 \mathrm{~kg} / \mathrm{m}^{3}$ of SF alone, in the concrete considered here. Consequently, when FRC with a hybrid combination of fibres (AMF+SF) was considered in design, a significant reduction in thickness of slab was possible, in comparison to FRC with only SF.
\end{abstract}

Keywords: Fibre reinforced concrete; Flexural toughness; Slabs-on-grade; Inelastic design

\section{Introduction}

Use of fibre reinforced concrete in applications such as slabson-grade is mainly advocated due to the enhanced material performance with respect to crack resistance. In order to take full advantage of the potential of the fibre reinforcement, it is essential that the material properties are appropriately accounted for in the design. In this sense, inelastic design approaches have been shown to be beneficial [1-7]. As an extension to these approaches, a design methodology has been developed addressing various possible failure patterns, and yielding a performance requirement as the output, which facilitates the use of different combinations of fibres and concretes [8]. The proposed method is used here to assess the advantage of using fibre combinations that result in significant improvement in flexural strength, as well as the post cracking resistance. A genre of corrosion-resistant amorphous metallic fibres (AMF) has been shown to have the ability to significantly enhance the flexural strength of concrete, even at relatively low dosages [9-12]. The current study explores the application of such fibres, in combination with conventional hooked-ended cold-drawn steel wire fibres (SF), in the design of FRC slabs-on-grade.

The paper also briefly explains the design methodology and the influence of each material parameter on the solutions obtained. Subsequently, the properties of concretes with the hybrid combinations of AMF and hooked-ended SF are summarised. The paper finally demonstrates the advantage of using such hybrid combinations in FRC slabs-on-grade to facilitate thickness reduction significantly.

\section{Proposed design methodology for FRC slabs- on-grade}

The present methodology employs, as material parameters, the flexural strength, $f_{c t}$, to represent the first-crack capacity and the equivalent flexural strength, $f_{e 150}$, to represent the post-crack capacity of the concrete, with $f_{\text {el50 }}$ obtained from a bending test on a concrete prism (as per JSCE SF4 1984 and ICI TC/01.1 2014) as the average post-cracking stress:

$f_{e 150}=\frac{T_{150} \times L}{\delta_{150} \times b d^{2}}$

where $T_{150}$ is the area under load deflection curve up to a deflection $\delta_{150}=L / 150$ (e.g., $3 \mathrm{~mm}$ in the case of $450 \mathrm{~mm}$ span); and $L, b$ and $d$ are the span, breadth and depth of the specimen [13-14]. The deflection limit is taken here as $L / 150$ in order to be conservative with respect to the allowable cracking and corresponds to the maximum deflection stipulated in most standard methods.

The main features of the design method are briefly given below, and a more detailed discussion, along with justifications, can be found in Nayar [15].

\footnotetext{
* Corresponding author: Ravindra Gettu, E-mail: gettu@iitm.ac.in
} 


\section{Assumptions/hypotheses:}

- The Winkler model is acceptable for representing the subgrade response.

- $\quad$ Fibres are uniformly and isotropically distributed in the concrete.

- $\quad$ The maximum rotation at the crack at failure load does not exceed 0.0267 radians (equivalent to the rotation for which the equivalent flexural strength is calculated in the material characterization test).

- It is acceptable to have open cracks at the bottom of the slab during service.

- The slab is considered to have reached the ultimate limit state when the crack opens at the top of the slab.

\section{Design philosophy:}

It is considered that the incorporation of suitable fibres in concrete imparts sufficient rotation capacity to the slab during cracking, permitting the mobilization of its plastic moment capacity. The ultimate load may then be estimated by considering rigid-plastic behaviour, with the yield lines forming a mechanism.

\section{Moment capacities:}

The post-cracking plastic moment capacity of the FRC slab is taken as a function of toughness and is estimated, per unit length of the slab, as:

$$
M_{P}=\frac{f_{e 150, k}}{\gamma_{m}} \frac{h^{2}}{6}
$$

where $f_{e l 50, k}$ is the characteristic equivalent flexural strength of concrete, $h$ is the thickness of the slab and $\gamma_{m}$ is the material safety factor.

The negative moment capacity will be a function of the flexural strength (or modulus of rupture) of the concrete (obtained from the same flexural test) as:

$M_{n}=\frac{f_{c t, k}}{\gamma_{m}} \frac{h^{2}}{6}$

where $f_{c t, k}$ is the characteristic flexural strength of the concrete.

\section{Safety factors in the design:}

The material safety factor $\gamma_{m}$ is taken to be same in Eqns. (2) and (3) for simplicity but could be different. Further, the value of $\gamma_{m}$ can be taken as 1.0-1.2, considering the level of reliability needed. The load safety factor is taken as 1.2 for all static loading cases and an additional dynamic factor of 1.5 is used in case of cyclic loading.

\section{Design steps:}

Step 1: Assessment of probable failure patterns: Based on the input regarding the load configuration, layout of the site, minimum grade of concrete, subgrade properties, etc., initial assumptions are made for the thickness and other dimensions of the slab. Based on these dimensions and the boundary conditions, the possible failure patterns are chosen [15] from the following options:

- D-shaped cracking (see Table 1), which occurs when the slab length is less than $10 \times$ radius of relative stiffness $(l)$ but more than $50 \%$ load transfer can be assumed at the joints or when there is a dominant edge loading. The value of $l$ depends on the subgrade response and is calculated as:

$$
l=\left[\frac{E h^{3}}{12\left(1-\mu^{2}\right) k}\right]^{1 / 4}
$$

- $\quad$ where $E$ is the modulus of elasticity of concrete, $\mu$ is the Poisson's ratio of concrete and $h$ is the thickness of the slab.

- Circular cracking (see Table 1) in the slab interior due to dominant point or wheel load. For such failure to occur, the load should be at a distance of at least $5 \times l$ from the edge or the load transfer mechanism at the edges has to be efficient enough for the slabs to behave monolithically.

- Transverse cracking across the slab width, which occurs when the slab is small enough for the edges to lift freely.

The two most predominant failure patterns, for slabs having load transfer capability at the edges, are shown in Table 1 , along with the corresponding design equations [15].

Step 2: Limiting moment analysis: Yield line analysis [16] is carried out for the expected failure patterns to obtain the inelastic moment function $f(P, c / l)$ for each critical load configuration:

$M_{\text {limiting }}=f(P, c / l)$

where $M_{\text {limiting }}$ is the limiting moment due to the applied load $P$, and $c$ is the load contact radius.

Step 3: Thermal and shrinkage stresses: The flexural stresses due to thermal effects, $f_{\Delta T}$, and those due to shrinkage, $f_{s h}$, are estimated using appropriate experimental/analytical models. The flexural stress due to the temperature differential $(\Delta T)$ in the slab can be estimated using the classical Bradbury's equation, as:

$f_{\Delta T}=\frac{E \alpha \Delta T}{2\left(1-v^{2}\right)}\left(C_{1}+v C_{2}\right)$

where $\alpha$ is the coefficient of thermal expansion, and $C_{1}$ and $C_{2}$ are the Bradbury's correction factors for curling in a finite slab, which can be obtained from charts prepared for various values of $B / l$, where $B$ is the joint spacing. The flexural stress associated with the moment due to shrinkage strain can be calculated as:

$f_{\text {sh }}=0.2 E \varepsilon_{\text {sh }}$

where $\varepsilon_{s h}$ is the ultimate shrinkage strain. In the absence of $\varepsilon_{\mathrm{sh}}$-data for the concrete used in the slab, a value between 300-500 microstrains may be assumed. 
Table 1. Design equation for D- and circular-cracking patterns

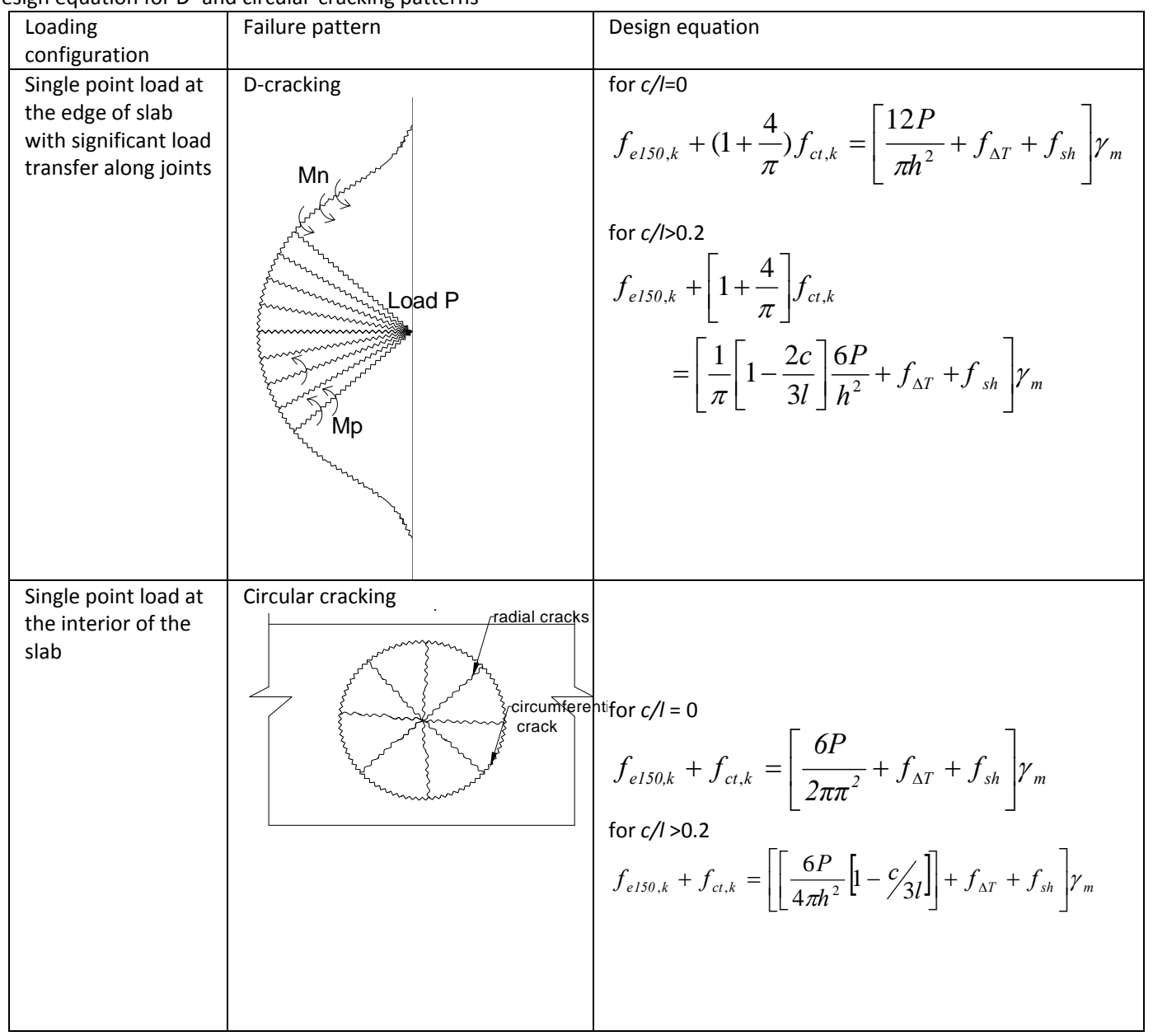

Table 2. Some values of constant $A$ to be used in Eqn. 10

\begin{tabular}{|l|l|l|l|}
\hline \multirow{2}{*}{ Load application } & Position of load & $\begin{array}{l}\text { Expected failure } \\
\text { pattern }\end{array}$ & $\mathbf{A}$ \\
\hline \multirow{3}{*}{ Point load } & Interior & Circular cracking & 1 \\
\cline { 2 - 4 } & Edge/Interior & D-cracking & $(1+4 / \pi)$ \\
\cline { 2 - 4 } & Interior & Centerline cracking & 0 \\
\hline \multirow{2}{*}{ Dual point load } & Interior & Circular/Semi-circular & 1 \\
\cline { 2 - 4 } & Edge & D-cracking & 1 \\
\hline $\begin{array}{l}\text { Quadruple point } \\
\text { loads }\end{array}$ & Interior & Circular/Semi-circular & 1 \\
\cline { 2 - 4 } & Edge & D-cracking & 1 \\
\hline
\end{tabular}

\section{Step 4: Design solutions:}

For cases where the limiting moment is represented by the sum of the plastic and negative moment capacities (i.e., for the circular and D-cracking cases), it is given as:

$M_{\text {limit }}=M_{n}+M_{p}$.

For other cases, where the limiting moment is only the plastic moment capacity (i.e., for centre line cracking), the moment capacity is:

$M_{\text {limit }}=M_{p}$

From the appropriate limiting moment capacity expression, the required $f_{c t, k}$ and $f_{e l 50, k}$ are obtained as:

$$
f_{e 150, k}+A f_{c t, k}=\left[\frac{6}{h^{2}} f\left(P, \frac{c}{l}\right)+f_{\Delta T}+f_{s h}\right] \gamma_{m}
$$

where $A$ is a constant that depends on the loading configuration and the slab-load interaction. For Meyerhof's ultimate load analysis, the values of $A$ for some possible loading conditions and failure patterns are provided in Table 2 (further details can be found in Nayar [15]).

Step 5: Design output: A combination of fibre type(s) and fibre dosage(s) is chosen such that the requirement of $f_{c t, k}$ and $f_{e 150, k}$ is satisfied, considering the given grade of concrete. From the parameters corresponding to the chosen FRC mix, preferably from test data, the limiting moments are calculated and the following check is made for the maximum allowable load $\left(P_{\text {allowable }}\right)$ :

$$
P_{\text {allowable }}>P
$$




\section{Influence of the material parameters on the design solution}

In order to illustrate the influence of the FRC material parameters, viz., $f_{c t, k}$ and $f_{e l 50, k}$ on the design solutions, a parametric study has been done by considering some hypothetical cases [15]. The design solutions are shown here for two cases, with single point loading, at the edge, resulting in D-cracking, and at the interior, resulting in circular cracking; the design equations are given in Table 1 for these two failure patterns. The input parameters are those shown in Table 3.

Table 3. Design input parameters for both trials

\begin{tabular}{|l|l|}
\hline Input parameter & Value \\
\hline Point load magnitude & $80 \mathrm{kN}$ \\
\hline Area of base plate & $100 \mathrm{~mm} \times 100 \mathrm{~mm}$ \\
\hline Modulus of subgrade, $k$ & $0.04 \mathrm{~N} / \mathrm{mm}^{3}$ \\
\hline Young's modulus of concrete & $21 \mathrm{GPa}$ \\
\hline Material safety factor, $\gamma_{m}$ & 1.0 \\
\hline
\end{tabular}

In the first trial, $f_{c t, k}$ was varied from 3.0 to $5.5 \mathrm{MPa}$ with increments of $0.5 \mathrm{MPa}$ keeping $f_{e l 50, k}$ constant at $3.0 \mathrm{MPa}$. In the second trial, $f_{e l 50, k}$ was varied from 3.0 to $5.0 \mathrm{MPa}$ keeping $f_{c t, k}$ constant at $4.0 \mathrm{MPa}$. The results from the two cases are plotted in Figure 1 . The plots show that in the case of edge loading, where $A=(1+4 / \pi)$, the design is more sensitive to changes in the flexural strength than the equivalent flexural strength, as reflected by the steeper slope of the plot for constant $f_{c t, k}$. For example, for an increase of about $40 \%$ in $f_{c t, k}$, the reduction in slab thickness is about $17 \%$ as opposed to a reduction of only $8 \%$ for the same increase in $f_{e l 50, k}$.

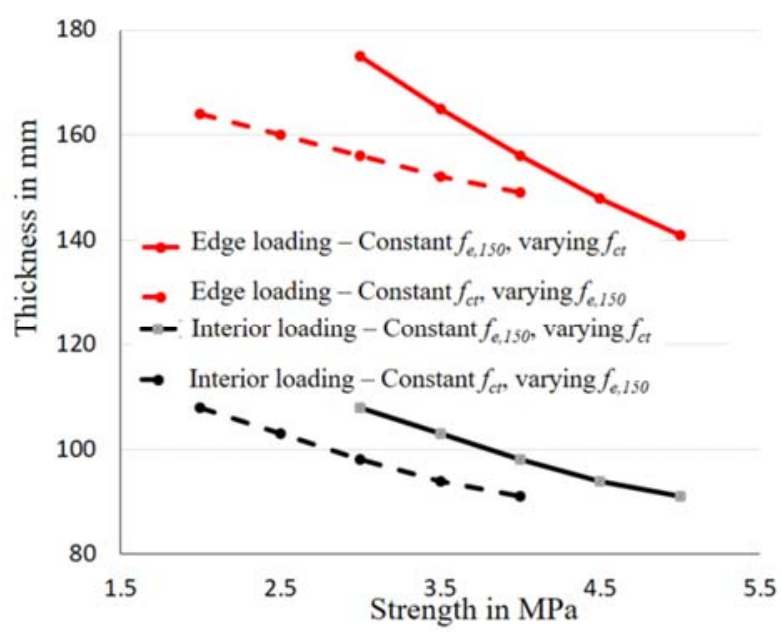

Figure 1. Variation of minimum required thickness with strength parameters

In the case of interior loading, with $A=1.0$, the influence of both parameters are the same, indicating that the optimum solution is obtained when both $f_{c t, k}$ and $f_{e l 50, k}$ are as large as possible.

In most cases, the critical failure pattern in slabs-on-grade is D-cracking, where the design is more sensitive to changes in the flexural strength. Therefore, it can be stated that generally fibres that improve flexural strength, in addition to providing the required post-cracking capacity, will be more beneficial.

\section{$4 \quad$ Flexural toughness properties of mixes with amorphous metallic and hooked ended steel fibres}

Amorphous metallic fibers (AMF), such as those fabricated with an iron-chromium alloy, are interesting because of their corrosion resistance and high tensile strength $[12,17]$. The incorporation of AMF in concrete could result in significant enhancement of the flexural and tensile strengths [9-12]. However, the influence of these fibers on toughness over larger crack widths is not encouraging [9, 12, 18-20]. On the other hand, cold drawn steel fibres are used conventionally in applications such as flooring, pavements, etc., to provide significant toughness to the concrete (e.g., Nayar et al. [21]). They, however, do not increase the flexural strength of the concrete at normal dosages. The combination of AMF with conventional steel fibres seems to be a suitable choice for increasing both the flexural strength and toughness of concrete, especially due to the consequent synergistic effect [12].

Flexural tests were performed on concretes with a design compressive strength of $35 \mathrm{MPa}$ (denoted as M35), and reinforced with different dosages of hooked-ended steel fibres (SF) and hybrid combinations with one dosage of SF and two dosages of AMF (see Table 4). The tests were done under third-point loading, on prisms of $150 \mathrm{~mm} \times 150 \mathrm{~mm} \times$ $700 \mathrm{~mm}$, with $450 \mathrm{~mm}$ span, as in the ICI TC/01.1 (2014) recommendation, similar to ASTM C 1609 [22]. The properties of fibres, mix proportions used and details of the experimental programme are reported elsewhere [12, 21]. The AMF are straight flat fibres of length $20 \mathrm{~mm}$ and cross section of $1 \mathrm{~mm} \times 24 \mu \mathrm{m}$ with a tensile strength of about $1400 \mathrm{MPa}$ and density of $7200 \mathrm{~kg} / \mathrm{m}^{3}$. The SF are collated, each of length $60 \mathrm{~mm}$ and cross section diameter of $0.8 \mathrm{~mm}$, with a tensile strength of $1225 \mathrm{MPa}$ and density of $7800 \mathrm{~kg} / \mathrm{m}^{3}$.

Table 4. Concretes tested

\begin{tabular}{|l|l|l|l|}
\hline Concrete & $\begin{array}{l}\text { Fiber } \\
\text { type }\end{array}$ & Dosage, $\mathbf{k g} / \mathbf{m}^{\mathbf{3}}$ & $\begin{array}{l}\text { Volume fraction, } \\
\%\end{array}$ \\
\hline F0 (Control) & - & 0 & 0 \\
\hline SF15 & SF & 15 & 0.20 \\
\hline SF20 & SF & 20 & 0.26 \\
\hline SF30 & SF & 30 & 0.38 \\
\hline S15AMF10 & SF & 15 & \multirow{2}{*}{0.34} \\
\cline { 2 - 3 } & AMF & 10 & \multirow{2}{*}{0.48} \\
\hline S15AMF20 & SF & 15 & \\
\cline { 2 - 3 } & AMF & 20 & \multicolumn{2}{|l}{} \\
\hline
\end{tabular}

The typical load-deflection curves of the different mixes are shown in Figure 2, with a significant increase in the peak load seen for the hybrid mixes with SF and AMF in comparison to the mix with same dosage $\left(15 \mathrm{~kg} / \mathrm{m}^{3}\right)$ of SF alone. The enhancement in peak load is seen to be substantially improved with an increase in AMF dosage (from $10 \mathrm{~kg} / \mathrm{m}^{3}$ to $20 \mathrm{~kg} / \mathrm{m}^{3}$ ) thus indicating that AMF influences the crack 
initiation resistance at the material level. On the other hand, the use of AMF only will not provide the toughness required for the desired rotation capacity at the cracks. The values of $f_{c t, k}$ and $f_{e l 50, k}$ obtained from the load-deflection responses are given in Table 5 .

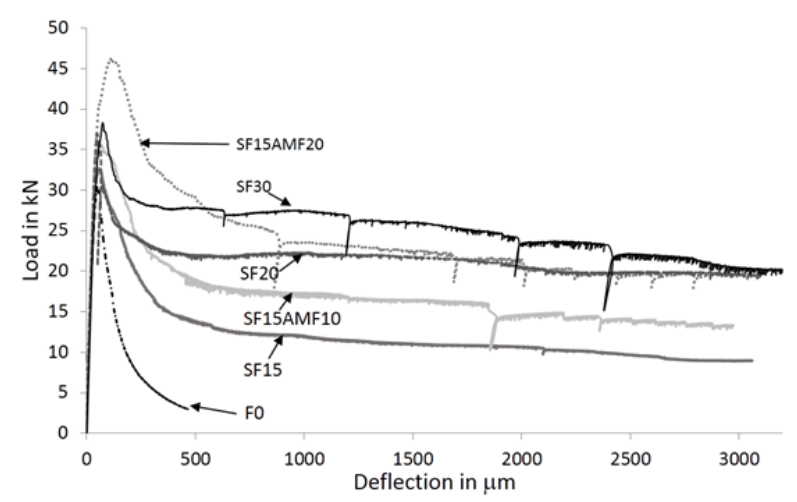

Figure 2. Typical load deflection curves of the various concretes tested

Table 5. Characteristic strengths
\begin{tabular}{|l|l|l|}
\hline Concrete & $f_{c t, k}(\mathrm{MPa})$ & $f_{\text {e150,k }}(\mathrm{MPa})$ \\
\hline F0 & 2.51 & 0.171 \\
\hline SF15 & 3.63 & 1.14 \\
\hline SF20 & 3.77 & 2.25 \\
\hline SF30 & 3.57 & 2.13 \\
\hline S15AMF10 & 4.13 & 2.34 \\
\hline S15AMF20 & 4.86 & 2.56 \\
\hline
\end{tabular}

From the comparison of results in Table 5, the most significant observation is the considerable increase in the flexural strength, $f_{c, t, k}$ of the concrete with the addition of AMF fibres. Concretes with the hybrid mixes with $15 \mathrm{~kg} / \mathrm{m}^{3}$ of SF and $20 \mathrm{~kg} / \mathrm{m}^{3}$ of AMF exhibit a $47 \%$ increase in $f_{c t, k}$ and $120 \%$ increase in $f_{\text {el50, } k}$ compared to the mix with $15 \mathrm{~kg} / \mathrm{m}^{3}$ of $\mathrm{SF}$ alone. Further, the synergistic effect of the hybrid reinforcement is evident when the $f_{e l 50, k}$ value of $2.17 \mathrm{MPa}$ estimated for a concrete with SF volume fraction of $0.34 \%$ (by interpolating between the appropriate values in Table 5) is seen to be significantly lower than the corresponding value for the SF15AMF10 mix, which is $2.34 \mathrm{MPa}$. More detailed discussion of the synergistic effect of the hybrid reinforcement can be found in Nayar and Gettu [12].

\section{Benefit of using hybrid fibre mixes in the design of slabs-on-grade}

It is proposed that in cases where slab thickness reduction is beneficial with respect to economy, material savings and ease of application, concrete with hybrid mixes of AMF and SF could be preferred over single fibre reinforcement. For demonstrating the benefit, a comparative study of design with hybrid and single fibres is described here, for typical two cases. The first case is a slab of $4 \mathrm{~m} \times 4 \mathrm{~m}$ with a point load of $80 \mathrm{kN}$ applied on a base plate of $150 \mathrm{~mm} \times 150 \mathrm{~mm}$, with the subgrade modulus, $k$, being $0.04 \mathrm{kN} / \mathrm{mm}^{3}$, and the second case is the same slab with $250 \mathrm{kN}$ point load applied on a base plate of $150 \mathrm{~mm} \times 150 \mathrm{~mm}$, with $k=0.17 \mathrm{kN} / \mathrm{mm}^{3}$; the design parameters are given in Table 6 and the solutions for M35 grade FRC are given in Table 7 in terms of minimum required fibre dosage and slab thickness. The required performance criterion in terms of $f_{c t, k}+A f_{e l 50, k}$ is also provided for reference.

The design solutions for the two cases indicate that the hybrid combination of fibres (AMF+SF) leads to a significantly lower slab thickness, mainly due to the increase in $f_{c t, k}$. In addition, considering the load-deflection behavior from the flexure test (Figure 2), at the same level of deflection, the slabs with FRC having hybrid combination would sustain higher loads in comparison to the FRC having only steel fibres. This would translate to higher crack resistance for the hybrid FRC slabs for the same load levels, leading to longer maintenance-free life. This advantage would be more pronounced in cases where fatigue loads are significant, since the resistance is directly related to crack control. An added advantage is the lower corrosion of the AMF that would also contribute to increasing the life of the slab even in the cracked state.

Table 6. Details of the design trials

\begin{tabular}{|l|l|l|}
\hline Design parameter & Case 1 & Case 2 \\
\hline Load, $P(\mathrm{kN})$ & 80 & 250 \\
\hline Modulus of subgrade, $k\left(\mathrm{~N} / \mathrm{mm}^{3}\right)$ & 0.04 & 0.17 \\
\hline Elastic modulus, $E(\mathrm{GPa})$ & 34 & 34 \\
\hline Material safety factors, $\gamma_{m}$ & 1.2 & 1.2 \\
\hline Thermal and shrinkage stresses $f_{\Delta T}+f_{s h}(\mathrm{MPa})$ & 1.5 & 1.5 \\
\hline Critical failure criteria & D-cracking due to edge load \\
\hline & For $c / l=0$ \\
& $f_{e l 50, k}+\left(1+\frac{4}{\pi}\right) f_{c t, k}=\frac{12 P}{\pi h^{2}}+f_{\Delta T}+f_{s h}$ \\
& For $c / 1>0.2$ \\
& $f_{e l 50, k}+\left(1+\frac{4}{\pi}\right) f_{c t, k}=\frac{16 P}{\pi h^{2}}\left(1-\frac{2 c}{3 l}\right)+f_{\Delta T}+f_{s h}$ \\
\hline
\end{tabular}


Table 7. Comparison of design solutions with various fibre combinations

\begin{tabular}{|c|c|c|c|c|c|}
\hline $\begin{array}{l}\text { Loading } \\
\text { case }\end{array}$ & $\begin{array}{l}\text { Fibre } \\
\text { combination }\end{array}$ & $\begin{array}{l}\text { Fibre } \\
\text { type }\end{array}$ & $\begin{array}{l}\text { Fibre dosages } \\
\left(\mathrm{kg} / \mathrm{m}^{3}\right)\end{array}$ & $\begin{array}{l}\text { Minimum } f_{e 150, k}+A f_{c t, k} \\
\text { required (MPa) }\end{array}$ & $\begin{array}{l}\text { Minimum thickness } \\
\text { required }(\mathrm{mm})\end{array}$ \\
\hline \multirow{4}{*}{ Case 1} & Single & SF & 15 & $1.5+(1+4 / \pi) 3.4=9.23$ & 190 \\
\hline & Single & SF & 20 & $2.3+(1+4 / \pi) 3.4=10.03$ & 180 \\
\hline & Hybrid & $\begin{array}{l}\text { SF } \\
\text { AMF }\end{array}$ & $\begin{array}{l}15 \\
10 \\
\end{array}$ & $1.4+(1+4 / \pi) 4.8=12.31$ & 150 \\
\hline & Hybrid & $\begin{array}{l}\text { SF } \\
\text { AMF }\end{array}$ & $\begin{array}{l}15 \\
20\end{array}$ & $2.1+(1+4 / \pi) 5.6=14.83$ & 130 \\
\hline \multirow{4}{*}{ Case 2} & Single & SF & 15 & $1.5+(1+4 / \pi) 3.4=9.23$ & 325 \\
\hline & Single & SF & 20 & $2.0+(1+4 / \pi) 3.4=9.73$ & 310 \\
\hline & Hybrid & $\begin{array}{l}\text { SF } \\
\text { AMF }\end{array}$ & $\begin{array}{l}15 \\
10\end{array}$ & $1.4+(1+4 / \pi) 4.8=12.31$ & 270 \\
\hline & Hybrid & $\begin{array}{l}\text { SF } \\
\text { AMF }\end{array}$ & $\begin{array}{l}15 \\
20\end{array}$ & $2.1+(1+4 / \pi) 5.6=14.83$ & 235 \\
\hline
\end{tabular}

\section{Conclusions}

The paper presents a design methodology for FRC slabs-ongrade with emphasis on the influence of material parameter on the design solution. The study shows the advantage of using a hybrid combination of amorphous metallic fibres and steel fibres as concrete reinforcement in slabs-on-grade, in terms of thickness reduction. The specific conclusions are as below:

- The suggested methodology incorporates flexural strength and equivalent flexural strength of FRC as the material parameters to represent the first cracking and post-cracking capacity in the design.

- The limiting moment estimate is done as per appropriate inelastic analysis and the design output is the required material performance in terms of flexural strength and equivalent flexural strength.

- The design solution, though dependent on both material parameters, is more sensitive to variations in the flexural strength in the critical cases.

- A hybrid combination of AMF and SF in concrete mixes is shown to result in a significant increase in flexural strength and sufficient post-cracking capacity or toughness, thereby qualifying as appropriate for the slabs-on-grade application. The hybrid mix in M35 grade concrete results in about $25 \%$ decrease in slab thickness in comparison to that with only SF.

\section{Acknowledgements}

The authors acknowledge the partial financial support to the first author through the Women Scientist Scheme A of the Ministry of Science \& Technology, Govt. of India (ref. SR/WOS-A/Et-1007/2015 (G)). The authors also acknowledge the support of Saint Gobain Seva and Bekaert India for having provided the fibres used in this study.

\section{References}

[1] M. di Prisco, M. Mauri, Fibre-Reinforced Concrete Industrial Flooring Slabs, Fiberfix-Badessi, A-Fibres Technology Pvt. Ltd., 2004.
[2] S. A. Altoubat, J. R. Roesler, D. A. Lange, K. A. Rieder, Simplified Method for Concrete Pavement Design with Discrete Structural Fibers, Constr Build Mater (2008) 22(3): 384-393. http://doi.org/ 10.1016/i.conbuildmat.2006.08.008

[3] A. Jansson, I. Löfgren, Design Methods for Fibre-Reinforced Concrete: A State-of-the-Art Review, Nordik Concrete Research (2008) 38: 31-46.

[4] fib Model Code for Concrete Structures, fib CEB-FIP, Lausanne, Switzerland, 2010.

[5] TR 34 Concrete Industrial Ground floors: A Guide to Design and Construction, The Concrete Society, UK, 2003.

[6] TR 34 Concrete Industrial Ground floors: A Guide to Design and Construction, The Concrete Society, UK, 2013.

[7] $\mathrm{ACl} 360 \mathrm{R}$ Guide to Design of Slab-on-Ground, American Concrete Institute, Detroit, USA, 2010.

[8] R. Gettu, S. K. Nayar, A Design Methodology for Fibre Reinforced Concrete Slabs-on-Grade, Proc. of 27th Biennial National Conference of the Concrete Institute of Australia in conjunction with the 69th RILEM Week conference (Concrete 2015), (Australia), 31 August - 2 September, 2015, RILEM Publications s.a.r.l., 443-452.

[9] P. Rossi, Mechanical Behaviour of Metal-Fibre Reinforced Concretes, Cement and Concrete Composites (1992) 14(1): 3-16. http://doi.org/ 10.1016/0958-9465(92)90034-S

[10] P. Casanova, P. Rossi, Analysis of Metallic Fibre-Reinforced Concrete Beams Submitted To Bending, Mater Struct (1996) 29: 354-361. https://doi.org/10.1007/BF02486343

[11] R. Hameed, F. Duprat, A. Turatsinze and A. Sellier, Mechanical Properties of Reinforced Fibrous Concrete Beams Under Reverse Cyclic Loading, Proc. of 1st International Conference on Sustainable Built Environment Infrastructures in Developing Countries, SBEIDCO, ENSET Oran (Algeria), (2009a), 271-278.

[12] S. K. Nayar, R. Gettu, Synergy in Toughness by Incorporating Amorphous Metal and Steel Fibres, ACI Mater J (2015) 112 (6): 821-827. https://doi.org/10.14359/51687857

[13] JSCE Part III-2 (SF1-SF4) Method of Tests for Steel Fiber Reinforced Concrete, Concrete Library of JSCE, Japan Society of Civil Engineers, 1984.

[14] ICl-TC/01.1 Test Methods for the Flexural Strength and Toughness Parameters of Fiber Reinforced Concrete, Indian Concrete Institute Technical Committee Recommendation, Indian Concr Inst J (2014) 15(2): 39-43.

[15] S. K. Nayar, Design of Fibre Reinforced Concrete Slabs-ongrade and Pavements, Doctoral Thesis, Department of Civil Engineering, Indian Institute of Technology Madras, Chennai, India, 2016.

[16] G. G. Meyerhof, Load Carrying Capacity of Concrete Pavements, J Aoil Mech Found Div (1962) 88(SM3): 89-116.

[17] K. Choi, D. Ku, Flexural Behaviour of Amorphous Metal-FiberReinforced Concrete, Structures and Buildings, Proc. Institution of Civil Engineers, Korea, 2014.

[18] R. Hameed, A. Turatsinze, F. Duprat, A. Sellier, Positive Synergy Between Metallic-Fibers: Effect on the Flexural Properties of Hybrid Fiber Reinforced Concrete ( HYFRC), Proc. of 1st International Conference on Sustainable Built 
Environment Infrastructures in Developing Countries, SBEIDCO, ENSET Oran (Algeria), 2009b: 279-286.

[19] R. Hameed, A. Turatsinze, F. Duprat, A. Sellier, Study on The Flexural Properties of Metallic-Hybrid-Fibre-Reinforced Concrete, Maejo International Journal of Science and Technology (2010) 4(02): 169-184.

[20] G. Pons, M. Mouret, M. Alcantara, J. L. Granju, Mechanical Behaviour of Self-Compacting Concrete with Hybrid Fibre Reinforcement, Mater Struct (2006) 40(2): 201-210. http://doi.org/10.1617/s11527-006-9131-y

[21] S. K. Nayar, R. Gettu, C. Sree Krishnan, Characterisation of the Toughness of Fibre Reinforced Concrete - Revisited in the Indian Context, Indian Concr J (2014) 88(2): 8-23.

[22] [ASTM C1609/C1609M-10 Standard Test Method for Flexural Performance of Fiber Reinforced Concrete (Using Beam with Third-Point Loading), American Society of Testing and Materials, USA, 2010. 